\section{Candidates for Space Observatory Optics: Pyrex and ULE Glasses Withstand Greater Force in Vacuum than Air}

Imagine delicate glass discs two meters in diameter floating with the ease of soap bubbles gliding in air. The unencumbered vacuum of outer space may provide just the hospitable environment needed to manufacture sensitive optics for a giant space surveillance observatory. T.A. Manning and D.A. Gregory from the University of Alabama in Huntsville in collaboration with D.S. Tucker and K.A. Herren of NASA Marshall Space Flight Center investigated the strength of Pyrex and Ultra Low Expansion (ULE) glasses in vacuum conditions. In the October issue of the Journal of the American Ceramic Society (p. 3318; DOI: 10.1111/ j.1551-2916.2007.01872.x), the researchers report that at room temperature, Pyrex and ULE glass discs showed 54\% and $82 \%$ greater average strength, respectively, in vacuum over discs tested in $1 \mathrm{~atm}$ air pressure.

To accomplish the strength tests, the researchers designed and built a strengthtesting device inside a vacuum chamber. During a test, a thin glass disc sample rested flat on three points while a spherical contact applied a downward load to the top disc surface. The researchers attribute part of the observed increase in strength of the materials in vacuum to the absence of subcritical crack growth commonly caused by water vapor.

Manning and colleagues also examined the impact of mild heat treatment on glass strength in vacuum. They held 12 samples of both materials at $200^{\circ} \mathrm{C}$ for $24 \mathrm{~h}$ in vacuum and then strength tested samples in vacuum at $50^{\circ} \mathrm{C}$. The glass transition temperature of Pyrex is $560^{\circ} \mathrm{C}$ and of ULE is $1000^{\circ} \mathrm{C}$. Heat treatment did not cause a statistically significant change in the strength of either material in vacuum.

The researchers look forward to learning whether the theoretical strength of the glasses can be obtained in space. "The logical and more ambitious extension of this experiment would be to actually melt glass under vacuum, shape and cool it to form glass discs, and then measure the strength of those discs in situ," they stated.

ASHLEY PREDITH

\section{Yb:YAG Ceramic Laser Produced by Solid-State Reactive Sintering}

Recent advances in high-performance InGaAs laser diodes emitting in the $0.9-1.1 \mu \mathrm{m}$ range have stimulated the interest in developing diode-pumped $\mathrm{Yb}^{3+}$ ceramic lasers. A team of researchers asso- ciated with the Chinese Academy of Sciences (Y. Wu, J. Li, Y. Pan, and J. Guo from the Shanghai Institute of Ceramics, in collaboration with B. Jiang, Y. Xu, and J. Xu from the Shanghai Institute of Optics and Fine Mechanics) have fabricated fully transparent Yb:YAG ceramics by a simple solid-state reaction, as they reported in the October issue of the Journal of the American Ceramic Society (p. 3334; DOI: 10.1111/ j.1551-2916.2007.01885.x).

The researchers used high-purity commercially available $\alpha-\mathrm{Al}_{2} \mathrm{O}_{3}, \mathrm{Y}_{2} \mathrm{O}_{3}$, and $\mathrm{Yb}_{2} \mathrm{O}_{3}$ powders that weighed in proportion to the stoichiometry of 1 at.\% Yb:YAG. They mixed these reagents by ball milling in anhydrous alcohol for $12 \mathrm{~h}$, adding a binder, dispersion medium, and $0.5 \mathrm{wt} \%$ tetraethyl orthosilicate as a sintering aid. The speed of the ball-milling machine was controlled to mix the powders evenly, but to avoid crushing the particles into smaller sizes, which could incorporate impurities. The research team dried and sieved the mixtures, and dry pressed them at $100 \mathrm{MPa}$ into $20 \mathrm{~mm}$ diameter disks. They then cold isostatically pressed the mixtures at $250 \mathrm{MPa}$, and removed organic components by calcining at $1000^{\circ} \mathrm{C}$. The material was vacuum sintered at $1730^{\circ} \mathrm{C}$ for $10 \mathrm{~h}$ and then annealed at $1450^{\circ} \mathrm{C}$ for $20 \mathrm{~h}$ in air. The researchers obtained highly transparent $1 \%$ Yb:YAG ceramics with a uniform grain size of $<10 \mu \mathrm{m}$, and a transmittance of about $80 \%$ in the visible and the nearIR regions. They observed that the phase of sintering from $1500^{\circ} \mathrm{C}$ to $1700^{\circ} \mathrm{C}$ had to be controlled for efficient grain growth without encapsulating the pores.

After annealing, the samples showed three strong absorption peaks centered at $916 \mathrm{~nm}, 941 \mathrm{~nm}$, and $968 \mathrm{~nm}$ corresponding to the ${ }^{2} \mathrm{~F}_{7 / 2} \rightarrow{ }^{2} \mathrm{~F}_{5 / 2}$ transition of $\mathrm{Yb}^{3+}$, and a weak absorption peak at $1030 \mathrm{~nm}$ attributed to the fluorescent effect of $\mathrm{Yb}^{3+}$. For laser experiments, the Yb:YAG ceramics were mirror polished on both surfaces. The input face was coated to be accessed by light from the $940 \mathrm{~nm}$ pump fiber-coupled laser diode while the output face was coated to allow a high transmission of the generated light at $1030 \mathrm{~nm}$. The laser cavity consisted of an input coupler flat dichroic mirror coated for antireflection at $940 \mathrm{~nm}$ and high reflection at $1030 \mathrm{~nm}$, and a concave mirror ( $R=300 \mathrm{~mm}$ ) with different transmissions, as the output coupler (OC). The laser threshold increased from $1.8 \mathrm{~W}$ to $2.1 \mathrm{~W}$ as the $\mathrm{OC}$ transmission increased from $4 \%$ to $10 \%$. The maximum output power $(1.02 \mathrm{~W})$ was obtained with a slope efficiency of $25 \%$ and an optical-to-optical efficiency of $15.4 \%$ when the transmission was $10 \%$.
The output power increased linearly with an increase of input power.

JOAN J. CARVAJAL

\section{Carbon Nanocubes Display Cubic Mesoporosity}

Nanoparticles with well-defined mesoporosities are currently of interest for applications involving adsorption, such as controlled drug release, energy storage, chromatography, and catalysis, because of their increased surface areas compared to bulk materials. Mesoporous silica spheres, fabricated using mature sol-gel chemistry, have been studied at length but mesoporous carbon particles are appealing due to their electrical conductivity and chemical inertness. In particular, the development of fuel cells, which rely on facile mass transport, would benefit from ordered mesoporous carbon particles with dimensions $\sim 100 \mathrm{~nm}$. The nanocasting approaches typically employed to prepare mesoporous carbon particles use as hard templates mesoporous silica particles, the removal of which requires either HF or strong bases. A newer, aerosol-based, selfassembly technique produces either polydisperse carbon spheres with disordered mesopores or fairly monodisperse carbon microspheres with ordered porosity. More recently, however, Z. Wang, F. Li, and A. Stein of the University of Minnesota developed a facile method for the direct synthesis of monodisperse carbon nanoparticles with ordered mesoporosity in high yield. The method involves copolymer templating within the confinement of a colloidal crystal and does not use HF or strong bases.

As reported in the October issue of Nano Letters (p. 3223; DOI: 10.1021/ nl072068j), the researchers infiltrated until fully wetted monolithic colloidal crystal templates composed of poly(methyl methacrylate) (PMMA) spheres (diameter $=416 \pm 11 \mathrm{~nm}$ ) with a homogeneous precursor solution (Pluronic F127-a triblock polymer surfactant $\left[\mathrm{EO}_{97} \mathrm{PO}_{69} \mathrm{EO}_{97}\right.$, BASF] - added to a mixture of phenolic resin, ethanol, and aqueous $\mathrm{HCl}$ and stirred for $6 \mathrm{~h}$ ). After removing the solvent by exposure to reduced pressure $(0.5 \mathrm{~mm} \mathrm{Hg})$ for $3 \mathrm{~h}$, the monoliths were thermally polymerized within a closed container at $100^{\circ} \mathrm{C}$ for $48 \mathrm{~h}$. Heating under flowing $\mathrm{N}_{2}$ at $400^{\circ} \mathrm{C}$ for $3 \mathrm{~h}$ and then at $900^{\circ} \mathrm{C}$ for $2 \mathrm{~h}$ yielded carbonaceous samples, which the researchers designated MSP-3. Assuming a fully crosslinked phenolic resin, the carbon yield was $94 \mathrm{wt} \%$.

The researchers used scanning electron microscopy to show that the pyrolized products contain nanoparticles with a bimodal size distribution: nanocubes with 